\title{
ALS Incidence in Nova Scotia Over a 20- Year-Period: A Prospective Study
}

\author{
J.P. Bonaparte, I.A. Grant, T.J. Benstead, T.J. Murray, M. Smith
}

\begin{abstract}
Objective: Previous studies have suggested that the incidence of amyotrophic lateral sclerosis (ALS) in Nova Scotia is relatively high and increasing over time. This study was performed to determine the current incidence of ALS in Nova Scotia and to compare this to data collected in 1984 and 1995. Methods: All physiatrists and neurologists were surveyed on a monthly basis over one year to record all new cases of ALS diagnosed in Nova Scotia. Data was compared to that collected using similar methods in 1984 and 1995. To validate our methods, we also performed a retrospective study using a provincial health care database. Results: There were 21 new ALS cases in Nova Scotia during the 2003 study period, yielding a crude incidence of 2.24/100,000. The age-adjusted incident rate for 2003 was 2.13 (95\% CI = 0.11-4.15). The age-adjusted rate for 1995 was $2.3(95 \% \mathrm{CI}=0.08-4.53)$ while the age-adjusted rate for 1984 was $2.22(95 \% \mathrm{CI}=0.13-4.32)$. Analysis of provincial health records identified 24 cases of ALS and an age-adjusted incidence of 2.44/100,000. Conclusions: The ageadjusted incidence of ALS in Nova Scotia has remained stable over the period 1984-2003. The incidence is similar to that reported in several other parts of the world.
\end{abstract}

RÉSUMÉ: Incidence de la SLA en Nouvelle-Écosse sur une période de 20 ans : étude prospective. Objectif : Selon certaines études antérieures, l'incidence de la SLA serait relativement élevée en Nouvelle-Écosse et elle serait à la hausse. Le but de cette étude était de déterminer l'incidence actuelle de la SLA en Nouvelle-Écosse et de la comparer à celles de 1984 et de 1995. Méthodes : Une enquête a été effectuée auprès de tous les physiatres et les neurologues sur une base mensuelle pendant un an pour recenser les nouveaux cas de SLA diagnostiqués en Nouvelle-Écosse. Ces données ont été comparées à celles obtenues au moyen de méthodes similaires en 1984 et en 1995. Nous avons également effectué une étude rétrospective dans une banque provinciale de données de soins de santé afin de valider nos méthodes. Résultats : Au cours de l'étude en 2003, il y a eu 21 nouveaux cas de SLA en Nouvelle-Écosse, soit une incidence brute de 2,24/100 000 habitants. Le taux d'incidence ajusté pour l'âge était de 2,13 (I.C. à 95\% : de 0,11 à 4,15) en 2003, alors qu'il était de 2,3 (I.C. à 95\%: de 0,08 à 4,53) en 1995 et de 2,22 (I.C. à $95 \%$ : de 0,13 à 4,32) en 1984. L'analyse du fichier provincial a identifié 24 cas de SLA pour une incidence ajustée pour l'âge de 2,44/100 000 habitants. Conclusions : L'incidence de la SLA ajustée pour l'âge en NouvelleÉcosse est demeurée stable entre 1984 et 2003 . L'incidence est semblable à celle qui a été rapportée dans plusieurs autres parties du monde.

Can. J. Neurol. Sci. 2007; 34: 69-73

Amyotrophic lateral sclerosis (ALS) is a progressive neurodegenerative disorder of motor neurons in the cerebral cortex, brainstem and spinal cord. Although ALS is uncommon, accurate incidence information is needed to determine the impact of the disease on the health care system. Furthermore, regional differences in ALS incidence and changes in incidence over time may provide clues regarding the etiology of the disease.

Numerous epidemiological studies of ALS have been conducted, most of which used retrospective methods. ${ }^{1-8}$ Many of these studies analyzed large geographic areas with unstable populations, creating methodological challenges with respect to complete case ascertainment and patient follow-up. A Medline search conducted in March 2005 yielded six prospective studies of ALS incidence ${ }^{9-14}$ with crude incidence rates ranging between 1.6 and 2.5 per 100,000 .

From the Faculty of Medicine (JPB), Division of Neurology (IAG, TJB), MS Unit (TJM), Department of Community Health \& Epidemiology (MS), Dalhousie University, Halifax, NS, Canada.

ReCEIVED July 11, 2006. ACCEPTED IN FINAL FORM NOVEMBER 23, 2006. Reprint requests to: Ian Grant, Division of Neurology, Halifax Infirmary, 1796 Summer Street, Halifax, Nova Scotia, B3H 3A7, Canada. 
There is debate as to whether the incidence of ALS is increasing or whether the higher rates noted in more recent studies reflect better case ascertainment and/or decreased disease competition in the elderly population. Sorenson et $\mathrm{al}^{7}$ found no increase in ALS incidence in Olmsted County, Minnesota between 1925 and 1998. In contrast, Seljeseth et $\mathrm{al}^{6}$ reported a doubling in deaths due to ALS in Norway from 1961 to 1994. Interestingly, the increase in ALS mortality occurred exclusively in individuals older than 65 years of age. This increase in ALS mortality in the $>65$ year old population may be due to better identification of the disease in this population or it may reflect fewer competing risks and improved overall life expectancy.

Research specific to Canadian populations is limited. A five year retrospective study ${ }^{8}$ in Newfoundland found an average incidence of 2.4/100,000 (95\% CI 1.9-3.1) between 2000-2004. The authors did not report whether there were changes in incidence over this time. Hudson et $\mathrm{al}^{15}$ conducted a 4-year study of ALS in Southwestern Ontario, Canada, in the 1980s and identified an average incidence of 1.63/100,000.

In Canada, ALS incidence has been most extensively studied in Nova Scotia. ${ }^{14}$ Using retrospective methods, Murray et al ${ }^{14}$ found the incidence of ALS to be 1.95 cases per 100,000 in Nova Scotia over a 10-year period between 1974-1984. Prospective data collection during the calendar year 1984 yielded a similar incidence. A higher incidence was found during the period 19791984 than in the period 1974-1979. Although this apparent increase was probably the result of improved case ascertainment, a true increase in incidence could not be excluded. Subsequently, the same group conducted another prospective study of ALS in Nova Scotia in 1995, and found no significant difference between the 1995 rate $(2.14 / 100,000)$ and the $1974-1984$ rate. ${ }^{16}$

These findings suggest that the Nova Scotia incidence is similar to that in other regions and that the crude incidence may be increasing. However, further study with prospective data collection separated by long intervals is needed to confirm this. Nova Scotia is well suited to this approach because 1) patients with ALS are almost invariably diagnosed by neurologists in this province, 2) prospective data from 1984 and 1995 exist, with which current data (obtained with similar methods) can be compared, and 3) Nova Scotia has a stable population. ${ }^{17}$

This study was performed to obtain updated prospective data on ALS incidence in Nova Scotia and to compare this to data collected in 1984 and 1995. A secondary purpose was to validate the 2003 data by comparing it to data obtained from a provincial epidemiological database.

\section{MeTHODS}

Study Area. In 2003, the population of Nova Scotia, Canada was $936,165 . .^{17,18}$ This population is relatively stable; of all Canadian provinces, Nova Scotia had the smallest change in population size between 1996 and 2001. ${ }^{17}$ In Nova Scotia, the publicly funded health care system is divided into nine districts with only one large tertiary care referral center for neurological disease.

Prospective Data Collection. Using a prospective approach, we identified all new cases of ALS in Nova Scotia over a oneyear period between March 1, 2003 and February 28, 2004. Cases were identified with the participation of all neurologists and physiatrists practicing in Nova Scotia. Although a prior study by Murray et al ${ }^{14}$ noted that all cases of ALS in Nova Scotia were diagnosed or confirmed by a neurologist, we chose to include physiatrists (in accordance with previous surveys in NS) to ensure complete ascertainment. Prior to the study, each physician was contacted via telephone, email and letter-mail explaining the study and data collection requirements. At the end of each study month, clinicians submitted a datasheet for all cases identified. Each physician was contacted at the end of each study-month by telephone to either confirm reported cases or to confirm that no new cases were identified. The survey methods were identical to those of previous surveys in 1984 and 1995.

Diagnostic Criteria. Amyotrophic lateral sclerosis was defined using the 1994 World Federation of Neurology Guidelines $^{19}$ to maintain consistency of criteria across survey periods. Cases were classified as proven, definite, probable, possible or suspected ALS according to these criteria. The type of ALS (i.e. classical ALS, progressive bulbar palsy, primary lateral sclerosis or progressive muscular atrophy) was recorded; all subtypes were included in the analysis in keeping with previous NS surveys.

Only cases diagnosed by either a neurologist or a physiatrist within the study period of March 1, 2003 to Feb 28, 2004 were included in the data analysis. Furthermore, only cases identified as being proven, definite or probable were included in the analysis. Only cases in which the individual was considered a resident of Nova Scotia (defined as an individual living in the province for at least one year) were included. Only patients over 18 years of age were included in the analysis.

Data Collected. All patient data was supplied by the reporting physicians. For each case, the following data was collected: El Escorial diagnosis, ${ }^{19}$ ALS type, date of symptom onset, family history of ALS, age at diagnosis, gender, and geographical location in NS as defined by health district.

Retrospective Data Collection. We conducted a retrospective study to validate our prospective data from the 2003 data collection year. In Nova Scotia, all practicing physicians submit records of all services and diagnoses to Medical Services Insurance. The Population Health Research Unit (PHRU) at Dalhousie University maintains these records in an electronic database. This database contains medicare and hospital data

Table: ALS variants among the 21 new cases diagnosed in Nova Scotia during the 2003 study year

\begin{tabular}{lc}
\hline Type of ALS & N \\
Classical & 16 \\
PBP & 3 \\
PLS & 1 \\
PMA & 1 \\
\hline * PBP-prograssive bulbar palsy, PLS-primary lateral sclerosis, PMA- \\
progressive muscular atrophy
\end{tabular}


including ICD9-CM ${ }^{20}$ diagnostic codes for each visit, as well as the specialty of the diagnosing physician. This information was used to independently estimate the incidence of ALS in Nova Scotia in the 2003 study period. Only patients diagnosed by a neurologist or a physiatrist were included in the final analysis. However, all ALS diagnoses made by general practitioners were identified and followed-up to determine if the diagnosis was made in error, prematurely or correctly. For the purposes of this study, an individual was considered to have had a diagnosis of ALS if he or she had any visit to a neurologist or physiatrist that resulted in ICD-9CM diagnosis code 335.20 (ALS) listed as the first diagnosis. Incident cases were defined as those diagnosed between March 1, 2003 and February 28, 2004. The four previous years (1999-2002) were also searched to exclude prevalent cases.

Statistical Analysis. Incidence rates were age adjusted to the 2001 Canadian standardized population ${ }^{17}$ using the direct method of age-standardization. All incidence rates were reported with $95 \%$ confidence limits based on standard error calculations. The Kruskal-Wallis test was used to determine if a significant difference exists between the age at time of diagnosis between 1984, 1995 and 2003 as well as between males and females.

\section{RESUlts}

Prospective Data. There were 21 new cases of ALS diagnosed in Nova Scotia during the study period, giving a crude incidence of 2.24/100,000. Fourteen were male (crude incidence $3.05 / 100,000$ ) and seven were female (crude incidence $1.46 / 100,000)$. The clinical forms of ALS in the cases identified are presented in the Table.

The age-adjusted incidence rate for 2003 was 2.13 (95\% CI = 0.11-4.15). The age-adjusted rate from previous studies in 1995 and 1984 was $2.3(95 \% \mathrm{CI}=0.08-4.53)$ and 2.22 (95\% CI $=0.13-4.32)$ respectively. The differences in ageadjusted ALS incidence among these studies are not significant (Figure 1).

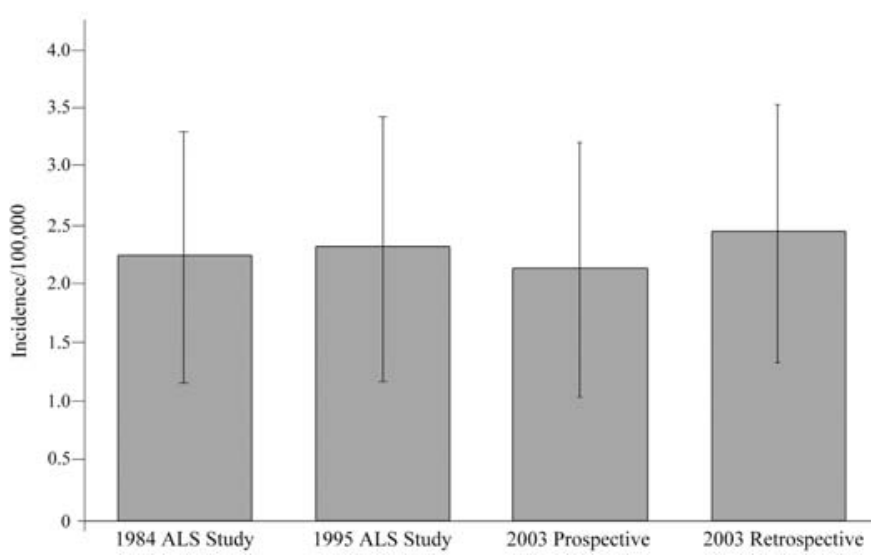

Figure 1: Comparison of age-adjusted incidence of ALS in Nova Scotia based on prospective data collection for 1984 (14), 1995 (16), and 2003 (present study) prospective and retrospective data.
The median age at diagnosis was 58 years with a range of 3477 years. Males and females were not significantly different with respect to median age at diagnosis $(p=0.34)$. There was no significant difference in median age at diagnosis between 1984, 1995 and 2003 studies ( $\mathrm{p}=0.14)$. The age profile of patients identified in the three prospective study periods is presented in Figure 2. One patient (4.7\% of total) identified during the 2003 study period had a family history of ALS.

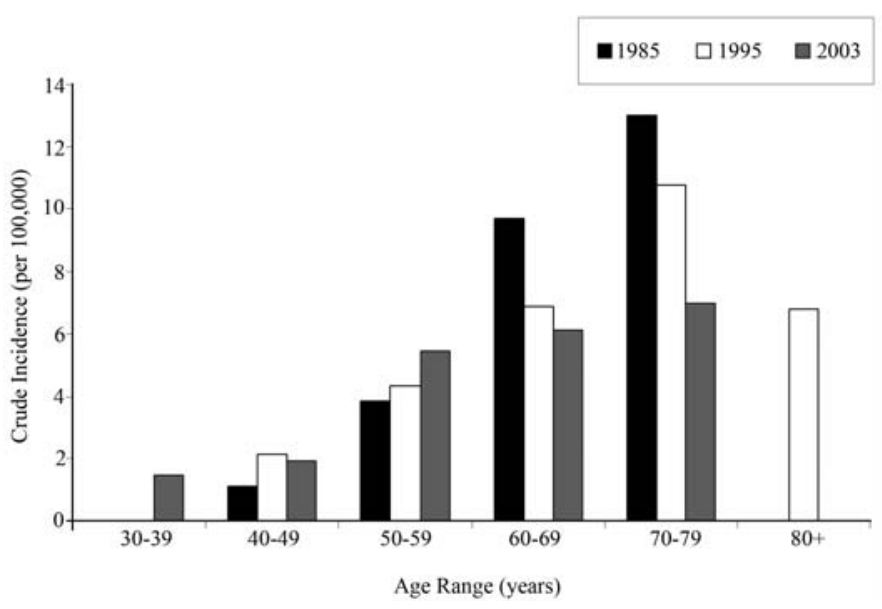

Figure 2: Age distribution of ALS cases in Nova Scotia. Values are crude incidence from the 1984, 1995 and 2003 collection periods.

Retrospective Data. The PHRU database identified a total of 35 cases. Eleven of these cases were coded by physicians who were not neurologists or physiatrists. Of these, seven subsequently saw a neurologist or physiatrist during the study year or the following year and were given a diagnosis other than ALS. The other four did not see a neurologist or physiatrist and were not considered to have a reliable diagnosis. Twenty-four were diagnosed by either a neurologist or physiatrist, giving a crude incidence of 2.56/100,000 with an age-adjusted incidence of $2.44 / 100,000$ (95\% CI $=0.27-4.6)$. This incidence is not significantly different from the result of the 2003 prospective survey.

\section{DisCUSSION}

The results of our study provide evidence that the incidence of ALS is not increasing in Nova Scotia and has remained stable since 1984. Although there has been a trend towards increasing crude incidence, age-adjusted incidence rates have remained stable. Comparing our current data to worldwide data from reviewed epidemiological studies, the crude Nova Scotia incidence is similar to other locations (Figure 3).

To validate the results of the prospective study, we conducted a retrospective review of billing records in Nova Scotia using the 


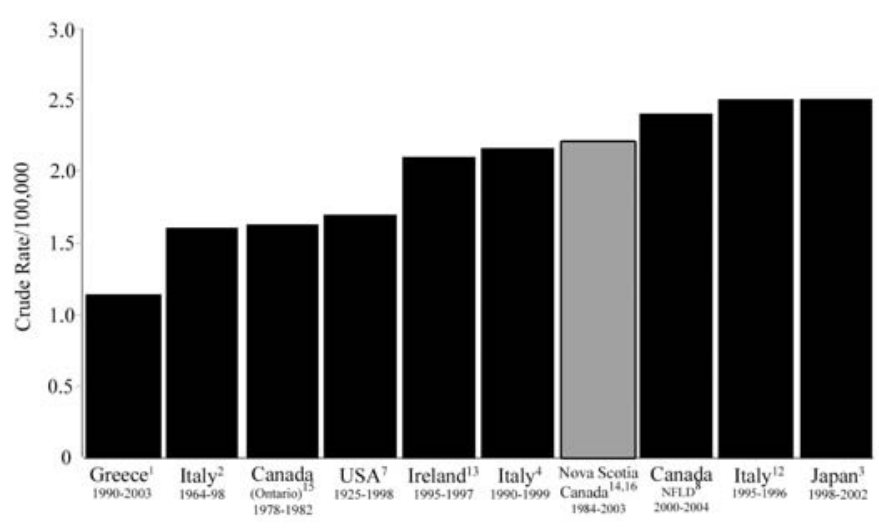

Figure 3: Comparison of crude ALS incidence rate in Nova Scotia with rates reported by studies performed in other geographical areas. Nova Scotia incidence represents the mean of the 1984, 1995 and 2003 data.

PHRU database. Analysis of the PHRU data identified a slightly larger number of individuals coded as ALS by either a neurologist or a physiatrist than was identified in the prospective survey. As the PHRU database contains billing records with minimal demographic information to ensure confidentiality, no clinical information for these additional cases is available. Therefore, it is possible that the additional cases coded as ALS were tentative or uncertain diagnoses, which were not considered appropriate to be reported prospectively by participating clinicians. The PHRU database also identified 11 patients diagnosed by physicians other than neurologists or physiatrists. Of these patients, four were never assessed by a neurologist or physiatrist within the study period, thus their diagnosis was doubtful. The diagnoses in the remainder were later revised such that the initial diagnosis of ALS was likely incorrect. Analysis of the PHRU data suggests that our calculated incidence from the prospective study is close to the true incidence, or at most a slight underestimation. Even if the PHRU data represent the true incidence, it cannot be concluded that the incidence of ALS in Nova Scotia is increasing.

Other studies addressing changes in ALS incidence over time have yielded conflicting results. One potential explanation is that many studies base their conclusions on crude incidence rates rather than age-adjusted rates. Given the aging population in many parts of the world as well as the well-established correlation between ALS incidence and increasing age, it is unreasonable to draw conclusions about changing incidence rates without considering the age of the population under study. Most studies using age-standardization methods have demonstrated little or no long-term increases in ALS incidence. None of the aforementioned prospective studies had sufficient long-term data to permit analysis of long-term changes in ageadjusted incidence. Long-term analyses have been retrospective in nature. Govoni et $\mathrm{al}^{2}$ reported that the incidence of ALS in Italy between 1964 to 1998 increased from 1.07 to 2.19 per 100,000 , but the authors suggested that this was likely a result of the aging of the population that occurred over this time period; the largest increase in incidence occurred in those over 65 years old, which directly corresponded to the large increase in population in that age group. In another long-term study, Sorenson et $\mathrm{al}^{7}$ conducted a retrospective review of ALS cases over the years of 1925-1998 and found no increase in ALS incidence over this time.

Physician survey studies have potential weaknesses. The reliability of diagnosis is dependent on the information provided by reporting clinicians and (in our study) could not be independently verified. Also, we have measured incidence at three discrete periods over 20 years; as there is inherent variability in incidence from year to year, our samples may be too small to detect small changes. However, the consistency of data collection methods used over 20 years and the characteristics of Nova Scotia's population and health care structure increase our confidence that our data represent a reasonably accurate picture of ALS in Nova Scotia over the study period.

Future studies using these methods are planned to continue to monitor the incidence of ALS in Nova Scotia.

The incidence of ALS in Nova Scotia has remained stable between 1984 and 2003. There is no evidence of increasing incidence based on age-adjusted incidence rates. We believe that we are able to obtain complete case ascertainment in Nova Scotia using the methods employed in the present study.

\section{ACKNOWLEDGEMENTS}

This study was supported by a grant from the Nova Scotia ALS Society.

\section{REFERENCES}

1. Argyriou AA, Polychronopoulos P, Papapetropoulos S, Ellul J, Andriopoulos I, Katsoulas G, et al. Clinical and epidemiological features of motor neuron disease in south-western Greece. Acta Neurol Scand. 2005;111(2):108-13.

2. Govoni V, Granieri E, Capone J, Manconi M, Casetta I. Incidence of amyotrophic lateral sclerosis in the local health district of Ferrara, Italy, 1964-1998. Neuroepidemiology. 2003;22(4): 229-34.

3. Kihira T, Yoshida S, Hironishi M, Miwa H, Okamato K, Kondo T. Changes in the incidence of amyotrophic lateral sclerosis in Wakayama, Japan. Amyotroph Lateral Scler Other Motor Neuron Disord. 2005;6(3):155-63.

4. Mandrioli J, Faglioni P, Merelli E, Sola P. The epidemiology of ALS in Modena, Italy. Neurology. 2003;60(4):683-9.

5. Sejvar JJ, Holman RC, Bresee JS, Kochanek KD, Schonberger LB. Amyotrophic Lateral Sclerosis mortality in the United States, 1979-2001. Neuroepidemiology. 2005;25(3):144-52.

6. Seljeseth YM, Vollset SE, Tysnes OB. Increasing mortality from amyotrophic lateral sclerosis in Norway? Neurology. 2000;55(9):1262-6.

7. Sorenson EJ, Stalker AP, Kurland LT, Windebank AJ. Amyotrophic lateral sclerosis in Olmsted County, Minnesota, 1925 to 1998. Neurology. 2002;59(2):280-2.

8. Stefanelli M, Lim C, Sloka J, et al. Iron Horse Disease - Are we overrun? The incidence of ALS in Newfoundland and Labrador, Canada. In: XVIIIth Conference of the World Congress of Neurology; 2005; Sydney, Australia; 2005. p. S214.

9. The Scottish Motor Neuron Disease Register: a prospective study of adult onset motor neuron disease in Scotland. Methodology, demography and clinical features of incident cases in 1989. J Neurol Neurosurg Psychiatry. 1992;55(7):536-41.

10. Logroscino G, Beghi E, Zoccolella S, Palagano R, Fraddosio A, Simone IL, et al. Incidence of amyotrophic lateral sclerosis in southern Italy: a population based study. J Neurol Neurosurg Psychiatry 2005;76:1094-8. 
11. McGuire V, Longstreth WT, Jr., Koepsell TD, van Belle G. Incidence of amyotrophic lateral sclerosis in three counties in western Washington state. Neurology. 1996;47(2):571-3.

12. PARALS. Incidence of ALS in Italy: evidence for a uniform frequency in Western countries. Neurology. 2001;56(2):239-44.

13. Traynor BJ, Codd MB, Corr B, Forde C, Frost E, Hardiman O. Incidence and prevalence of ALS in Ireland, 1995-1997: a population-based study. Neurology. 1999;52(3):504-9.

14. Murray TJ, Cameron J, Heffernan LP, MacDonald HN, King DB, Bedwell SR, et al. Amyotrophic lateral sclerosis in Nova Scotia. Adv Exp Med Biol. 1987;209:345-9.

15. Hudson AJ, Davenport A, Hader WJ. The incidence of amyotrophic lateral sclerosis in southwestern Ontario, Canada. Neurology. 1986;36(11):1524-8

16. Murray TJ, Traynor BJ. Incidence of amyotrophic lateral sclerosis in Nova Scotia 1986-1996. In: International Alliance of ALS/MND Associations 7th International Symposium; Chicago, USA; 1996.
17. Statistics Canada [online]. Population and Dwelling Counts, for Canada, Provinces and Territories, 2001 and 1996 Censuses. Updated: July 16, 2002. Last accessed June 2006. Available from:http://www12.statcan.ca/english/census01/products/ standard/popdwell/Table-PR.cfm.

18. Statistics Canada CANSIM II [online]. Estimates of population, by age group and sex, Canada, provinces and territories, annual (Persons unless otherwise noted). Table 051-0001. Last accessed June 2006. Updated May 26, 2006. Available from: http://cansim2.statcan.ca/.

19. Brooks BR. El Escorial World Federation of Neurology criteria for the diagnosis of amyotrophic lateral sclerosis. Subcommittee on Motor Neuron Diseases/Amyotrophic Lateral Sclerosis of the World Federation of Neurology Research Group on Neuromuscular Diseases and the El Escorial "Clinical limits of amyotrophic lateral sclerosis" workshop contributors. J Neurol Sci. 1994; Jul124 Suppl:96-107.

20. Medicode, ed. ICD-9-CM: international classification of diseases, clinical modification. 5th ed., 9th rev ed. Salt Lake City, UT: Medicode Inc; 1999. 